Original Article

\title{
ASSESSMENT OF PHARMACIST MEDIATED EDUCATION ON MEDICATION ADHERENCE BEHAVIOR IN TYPE 2 DIABETES MELLITUS PATIENTS IN SOUTH INDIAN RURAL POPULATION
}

\author{
SAI PAWAN RAMESH ADEPU ${ }^{1}$, STENY SAM ${ }^{2}$, CUCKOO OMANAKUTTAN ${ }^{3}$, RAMANATH K V ${ }^{4}$, YEGURLA \\ YASHASWINI $^{*}$
}

1,2,3,4 Student, SAC College of Pharmacy, RGUHS Bangalore, ${ }^{5}$ Student, JSS College of Pharmacy, JSS University Mysore

Email: yegurlayashaswini@gmail.com

Received: 25 May 2018 Revised and Accepted: 24 Jul 2018

\begin{abstract}
Objective: To assess the influence of pharmacist mediated education on medication adherence behavior (MMAS-8) in rural patients with type 2 diabetes mellitus.

Methods: This is a prospective, randomized interventional study approved by the institutional ethics committee. Eligible type 2 diabetic patients with written informed consent were enrolled and randomized into control and test group. The MMAS- 8 questionnaire was administered to all patients at baseline and three subsequent follow-ups. Patients in the test group received structured education at every follow-up, whereas the control group patients received education only at the final follow up. SPSS software was used to evaluate the data.

Results: Among the 72 patients enrolled, 35 were randomized into a control group and 37 into the test group. Majority of the study patients $(65.2 \%)$ were males with an age range of 30 to $72 \mathrm{y}$ and were from agriculture profession (34.72\%) with school education (59.7\%). The mean body mass index (BMI) of the study patients was 25.01. At baseline, the mean glycosylated hemoglobin (HbA1c) value of patients was $6.48 \pm 1.39 \%$ in the control group and $6.23 \pm 1.16 \%$ in the test group. During the last follow-up, a significant $(p<0.05)$ improvement was observed in MMAS-8 scores in test group patients compared to control group patients which were supported by statistically significant $(p<0.05)$ improvement in capillary blood glucose (CBG) values.
\end{abstract}

Conclusion: Pharmacist mediated structured education has shown a positive impact on medication adherence behavior of test group patients towards their disease management.

Keywords: Diabetes, Therapeutic outcome, Medication adherence behavior

(C) 2018 The Authors. Published by Innovare Academic Sciences Pvt Ltd. This is an open access article under the CC BY license (http://creativecommons.org/licenses/by/4.0/) DOI: http://dx.doi.org/10.22159/ijpps.2018v10i9.27543

\section{INTRODUCTION}

Diabetes mellitus (DM) is a metabolic disorder characterized by hyperglycemia. Increasing at an alarming pace particularly in developing countries [1] and it is estimated that, globally about 382 million people are suffering from diabetes [2]. According to the World Health Organisation (WHO), diabetes will be the $7^{\text {th }}$ leading cause for death in 2030 [3]. The global expenditure due to diabetes is estimated to be 548 US billion dollars and in India, it is estimated to be 6 billion US dollars and the mortality rate is about 55\% [2].

Patient's poor knowledge on the disease and its management and medication non-adherence lead to inadequate management of diabetes. Studies have confirmed about the positive influence of pharmacist mediated education on knowledge, attitude, and practices about disease and therapy which has shown a positive impact on health-related quality of life $[4,5]$.

Patient education is the most effective way to improvise patient responsibility towards disease management and minimize the diabetes complications and improve the outcomes [6]. This corroborates the importance of awareness among diabetics in DM management.

Research evidence available are suggesting the influence of pharmacist mediated patient education in improving medication adherence and good glycaemic control along with reduced diabetesrelated complications [7]

Medication adherence is defined as the extent to which a patient's medication-taking behavior coincides with the intention of the health advice he or she has been given. It is the most important factor that determines therapeutic outcomes, especially in patients suffering from a chronic illness like diabetes mellitus. The pharmacist can contribute and play a major role in the assessment of patients understanding about the illness and the therapy and communicate the benefits of treatment and assess the patient's readiness for the care plan and discuss any barriers to adherence that patients may have $[8,9]$.

Many studies have suggested that pharmacist role in medication adherence has a significant positive impact on health outcomes. A systemic review of the literature on the role of the pharmacist suggested that a potential benefit of pharmacist interventions was observed in improving medication adherence behavior in diabetes, especially through patient education.

A study conducted by R Adepu et al. that assessed the medication adherence behavior using Brief Medication Questionnaire (BMQ) and adherence risk scale (ARS) in type 2 DM patients receiving pharmacist mediated structured education demonstrated a significant improvement in medication adherence and final CBG values $\left({ }^{*} p=0.003\right)[10]$.

Another systematic review by Sujatha Sapkota et al. including 52 studies discussing medication adherence behavior in type 2 DM patients reported improvement in adherence to anti-diabetic medications in 22 interventions and nine interventions showed improvement in anti-diabetic medication adherence as well as glycaemic control [11].

\section{MATERIALS AND METHODS}

\section{Methodology}

This is a prospective interventional study conducted in medicine outpatient department of Adichunchanagiri Hospital and Research Centre, Mandya, Karnataka, India, over a period of 6 mo. Type 2 DM 
patients of both genders meeting the inclusion criteria were enrolled in the study using block randomization technique to avoid selection bias. Type 2 diabetes mellitus patients with disease duration of less than 3 y were included.

Paediatric, gestational diabetes and psychiatric patients were excluded from the study.

This study was approved by the institutional human ethics committee and issued a letter to conduct the study AIMS/IEC/1910.

Prior to initiating the study, the knowledge level of the surrounding community helps in selecting appropriate population and the level of awareness to be provided can be known.

A suitably designed data collection form was developed, details like patient demographics, educational status, social habits, socioeconomic status, past medical history and past medication history, family history, allergies, BMI, diet, marital status, smoking and alcohol status were obtained.

Morisky Medication Adherence Scale (MMAS-8) 8 item questionnaire was administered at baseline to assess the medication adherence behavior. The questionnaire assesses various areas of medication adherence behavior. There are a total of 8 questions, with a range from 0 to 8 [12-14]. This questionnaire was completed by the patient or patient attender at face to face interview with the investigator.

HbA1c was performed at baseline to assess the diabetic status of the enrolled patients. All the enrolled patients were followed for 3 mo from baseline with an interval of $30 \mathrm{~d}$ between the follow-ups. At every follow-up visit, BP and CBG were recorded that is fasting blood sugar (FBS) and postprandial blood sugar (PPBS). Test group patients received the pharmacist mediated structured education regarding the disease, medication, diet, and lifestyle modification at baseline and further follow-ups and received patient information leaflet. The control group patients received detailed education only at the final follow-up visit.

\section{Statistical analysis}

Results were analysed using Statistical Package for the Social Sciences (SPSS) for Windows Version 20. The significance of the change in CBG at each follow-up visit compared to first follow-up was assessed using independent t-test. The significance of the change in MMAS 8 scores from baseline to final follow-up was also assessed using a paired t-test. $p$ value of $<0.05$ is considered as significant.

\section{RESULTS}

A total of 72 eligible type 2 DM patients meeting the inclusion criteria were enrolled into the study. These patients were randomized into control and test group, 35 patients were from the control group and 37 patients were from the test group. $65.27 \%$ were males and $34.73 \%$ were females. The minimum age of the patients was $30 \mathrm{y}$ and maximum age of the patients was $72 \mathrm{y}$. The mean $( \pm$ SD) age of test group patients was $51.29 \pm 10.82 \mathrm{y}$ and that of the control group patients was $58.05 \pm 12.75 \mathrm{y}$. The majority of the enrolled patients were literate $(79.16 \%)$, with most of the patients having completed primary schooling education (59.7\%), who were farmers, daily wage laborers, and small business by profession since they belonged to the rural population.

The demographic details of the patients who had completed all the follow-ups are presented in table 1.

Table 1: Demographic characteristics

\begin{tabular}{|c|c|c|c|c|c|}
\hline \multirow{2}{*}{$\begin{array}{l}\text { Parameter } \\
\text { Gender }\end{array}$} & \multicolumn{2}{|c|}{ Control $(n=35)$} & \multicolumn{2}{|c|}{ Test $(n=37)$} & \multirow[t]{2}{*}{$p$ value $(<0.05)$} \\
\hline & No & $\%$ & No & $\%$ & \\
\hline - Male & 18 & 25 & 29 & 40.27 & 0.937 \\
\hline - Female & 17 & 23.6 & 8 & 11.1 & \\
\hline \multicolumn{6}{|l|}{ Age } \\
\hline - $\quad 30-40$ & 4 & 5.5 & 8 & 11.1 & 0.813 \\
\hline - $41-50$ & 8 & 11.1 & 10 & 13.8 & \\
\hline - $51-60$ & 9 & 12.5 & 10 & 13.8 & \\
\hline - 61 and above & 14 & 19.4 & 9 & 12.5 & \\
\hline \multicolumn{6}{|l|}{ Educational qualification } \\
\hline - Illiterate & 11 & 15.2 & 4 & 5.5 & 0.866 \\
\hline - Primary school & 11 & 15.2 & 9 & 12.5 & \\
\hline - Secondary school & 9 & 12.5 & 13 & 18.05 & \\
\hline - PUC & 3 & 4.1 & 4 & 5.5 & \\
\hline - Graduate & 0 & 0 & 6 & 8.3 & \\
\hline - Post Graduate & 1 & 1.3 & 1 & 1.3 & \\
\hline \multicolumn{6}{|l|}{ Profession } \\
\hline - Agriculture & 14 & 19.4 & 11 & 15.2 & 0.900 \\
\hline - Business & 4 & 5.5 & 12 & 9.72 & \\
\hline - Employment & 2 & 2.7 & 7 & 9.72 & \\
\hline - Housewife & 15 & 20.8 & 7 & 9.72 & \\
\hline \multicolumn{6}{|l|}{ Smoking status } \\
\hline Yes & 2 & 2.7 & 7 & 9.72 & 0.844 \\
\hline No & 33 & 45.8 & 30 & 41.6 & \\
\hline \multicolumn{6}{|l|}{ Alcoholic status } \\
\hline Yes & 7 & 9.72 & 13 & 18.05 & 0.874 \\
\hline No & 28 & 38.8 & 24 & 33.3 & \\
\hline
\end{tabular}

The mean BMI of the male patients was $24.76 \%$ and female patients were $25.27 \%$. Majority of the patients $(62.5 \%)$ had an average annual income of Rs. 50,000 to Rs. 1,00,000 and the rest of the patients were homemakers. The percentage of smokers in the control group and test groups were $11 \%$ and $24 \%$ respectively. Alcoholic status of patients in the control group was $39 \%$, and the test group was $45 \%$.

At baseline HbA1c test was conducted to know the diabetic status of the enrolled patients. The mean HbA1c value was $6.48 \pm 1.39 \%$ in the control group patients and $6.23 \pm 1.16 \%$ in the test group patients.
At First follow-up and subsequent follow-ups, CBG for FBS and PPBS was monitored to assess the influence of educational intervention on medication adherence behavior and glycaemic control. In the control group at the first follow-up, the mean FBS was $133 \mathrm{mg} / \mathrm{dl}$ and mean PPBS was $180 \mathrm{mg} / \mathrm{dl}$. In the final follow-up, the mean FBS was 132 $\mathrm{mg} / \mathrm{dl}$ and the mean PPBS was $175 \mathrm{mg} / \mathrm{dl}$. These values suggest that the glycaemic control did not change in the control group patients. Whereas the mean FBS during the first follow-up in test group patients was $123 \mathrm{mg} / \mathrm{dl}$ and mean PPBS was $175 \mathrm{mg} / \mathrm{dl}$. In the final follow-up, the mean FBS was $105 \mathrm{mg} / \mathrm{dl}$, and the mean PPBS was $133 \mathrm{mg} / \mathrm{dl}$. 


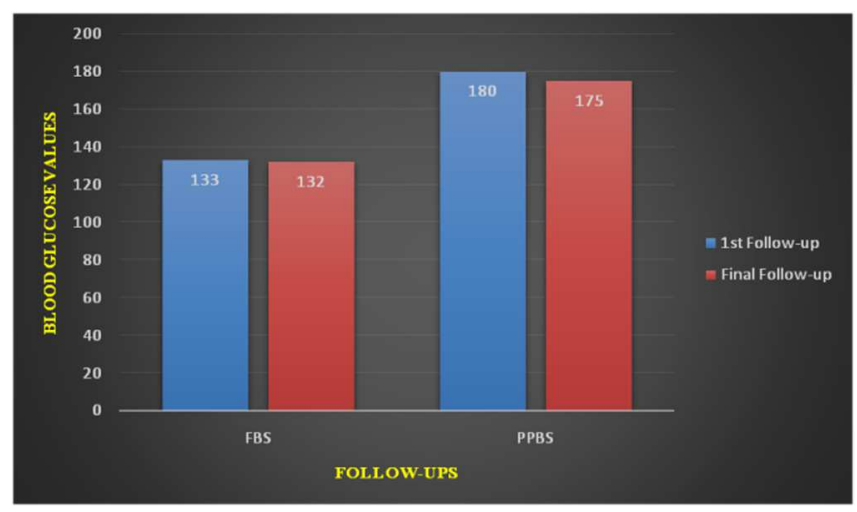

Fig. 1: Mean fasting blood sugar and mean postprandial blood sugar in control group

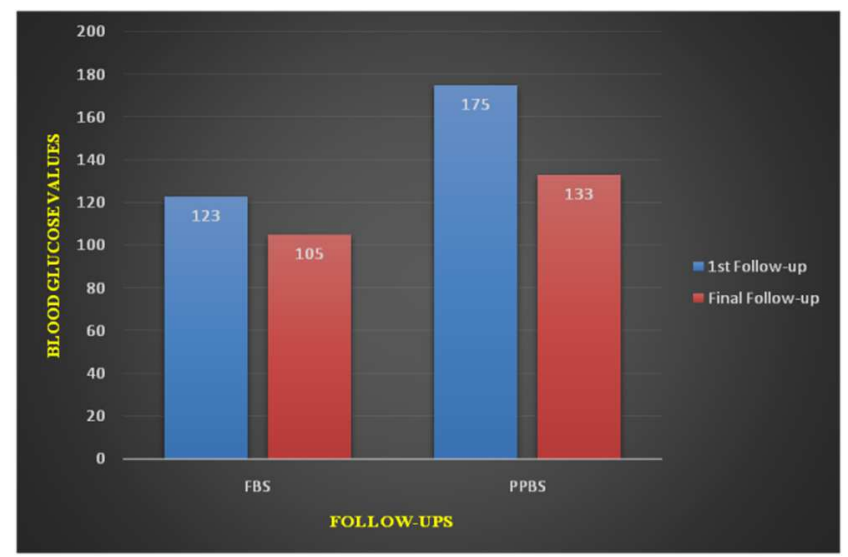

Fig. 2: Mean fasting blood sugar and mean postprandial blood sugar in the test group

Medication adherence behavior is the important predictor in the disease management. In subjective testing, MMAS- 8 is a validated tool to assess the medication adherence behavior in the patients. In the control group at baseline mean HbA1c was $6.48 \pm 1.39 \%$, mean MMAS- 8 score at baseline was 4.39 and by the end of the final follow-up mean MMAS-8 score was 4.9.

In the test, mean group HbA1c was $6.23 \pm 1.16 \%$, mean MMAS-8 score was 4.26 at baseline, and by the end of the final follow-up, it was increased to 7.89. Similarly, mean FBS and PPBS values in control group at first follow-up were $133 \mathrm{mg} / \mathrm{dl}$ and $180 \mathrm{mg} / \mathrm{dl}$ respectively, at final follow-up were $132 \mathrm{mg} / \mathrm{dl}$ and $175 \mathrm{mg} / \mathrm{dl}$ respectively. In the test group mean FBS and PPBS at first follow-up was $123 \mathrm{mg} / \mathrm{dl}$ and $175 \mathrm{mg} / \mathrm{dl}$ respectively, and at final follow-up was $105 \mathrm{mg} / \mathrm{dl}$ and $133 \mathrm{mg} / \mathrm{dl}$ respectively. This clearly states that educational intervention had a significant impact from baseline to final follow-up with the objective evidence through $\mathrm{HbA1c}$ values and CBG values and subjective evidence through the MMAS- 8 scores of control and test group. Thus it is clear that medication adherence behavior had a significant impact on test group patients with structured patient education.

In control group patients the mean MMAS-8 score in the baseline was 4.26, the first follow-up was 4.42, second follow-up was 4.57, and third follow-up was 4.90 . Whereas in the test group patients mean MMAS-8 score in the baseline was 4.39, first follow-up was 6.12, the second follow-up was 7.31 and third follow-up was 7.89. A significant improvement was seen in test group patients $(p<0.05)$ in MMAS- 8 scores. The findings of MMAS-8 scores of both control and test group are presented in fig. 3.

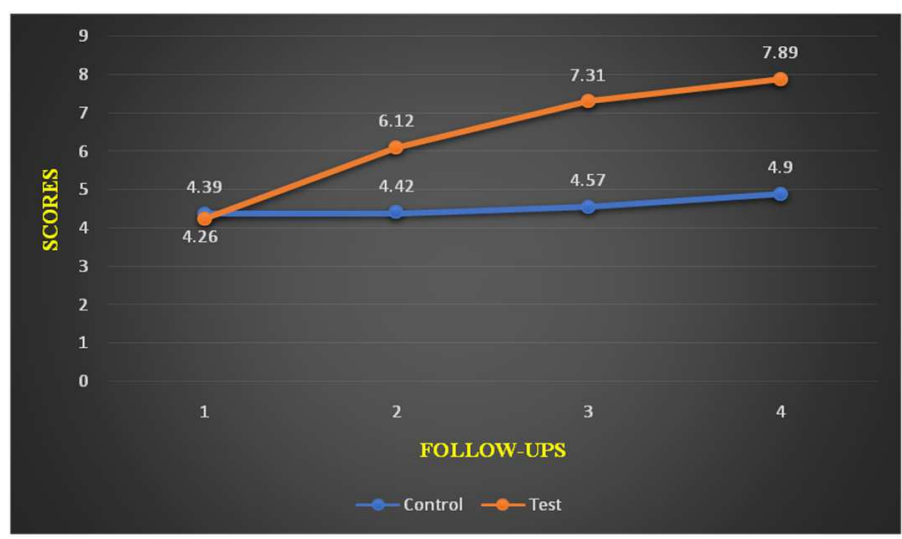

Fig. 3: Morisky medication adherence scores ${ }^{1},{ }^{1}$ use of the @MMAS is protected by US copyright laws. Permission for use is required. A license agreement is available from Donald E. Morisky, 294 Lindura Court, Las Vegas, NV 89138-4632; dmorisky@gmail. com 


\section{DISCUSSION}

Diabetes is a chronic disease and important public health problem nationally, internationally and the global prevalence of diabetes is on the rise. Inadequate management of diabetes leads to several health problems with increased risk of complications. This is mainly associated with the patient's poor knowledge about the disease and its management. Pharmacists by virtue of their professional status act as a liaison between the clinicians and patients not only by dispensing the prescribed medications but also assists the patients in the safe use of prescribed medicines and thereby enhancing their medication adherence behavior and thereby improving the healthrelated quality of life.

A total of 72 patients were included in the study. Males (65.2\%) outnumbered females (34.73\%), and a maximum number of patients $23(31.9 \%)$ were in the age group of 61 and above, which is similar to the study conducted by K V Ramnath et al. [15].

Literacy rate in our study was 57 (79.16\%) patients which eased structured patient counselling with the usage of patient information leaflet (PIL), as they could recall the information reading PIL at home, which was similar to the study conducted by Malathy $\mathrm{R}$ et al., Adepu R et al. and K V Ramnath et al. [5, 10, 15-17].

Medication nonadherence is another multifaceted problem especially for chronic diseases which plays an important role in determining the therapeutic outcomes. Studies have confirmed about the positive influence of pharmacist mediated education on knowledge, attitude, and practices about the disease and therapy which has shown a positive impact on medication adherence behaviour and positive health-related quality of life [4].

Patients with family history of diabetes were much aware of the role and responsibility in keeping their glycaemic status under control through proper diet, medication adherence and lifestyle modifications, with $26(36.11 \%)$ of patients having a family history of DM. A study conducted by Shobana et al. showed similar results. Similarly, educational status had a positive impact [18].

It is surprising to see $47(63.8 \%)$ of the patients have no family history of diabetes and were in the age group of 40-60 y. This probably indicates diabetes is emerging rapidly in the general population with various habits like increased intake of fats, highcalorie diet, beverages, cool drinks and junk food. A sedentary lifestyle with least or no exercise/physical activity, stressful, challenging corporate lifestyle with increased job demands, social status. Current younger generation possesses a greater risk due to stressful and sedentary lifestyle.

Nine (12.5\%) patients in our study were smokers and 20 (27.7\%) were alcoholic which has adverse effects on diabetes. Majority of the patients were neither alcoholic nor smokers which decreased the risk of complications, which was similar to the study conducted by $\mathrm{K}$ V Ramanath et al. [17].

Diabetic patients often develop complications due to inadequate glycaemic control mainly because of poor practices regarding the disease and management [5]. Patient education is the most effective way to improvise patient's responsibility towards disease management and minimize the diabetes complications and improve the health outcomes. Diabetic patients who wish to lead a normal life should understand about their illness and the strategies to put the disease under control [6]. This corroborates the importance of awareness among diabetics on DM management.

Medication adherence is a key element in the whole disease management process. Many predictors will influence the adherence behavior in patients. One among them is knowledge about the disease and the key role of medicines in its management. If patients are well informed about these, certainly they will take the responsibility of managing their disease through improved medication adherence behaviour. In the present study, a significant improvement in the medication adherence behaviour is observed in test group patients $(p<0.05)$. Adherence behaviour will reflect on health outcomes that can be vouched by FBS and PPBS values. In the study, population adherence behaviour was significantly improved in test group patients due to pharmacist mediated intervention. The healthcare provider support in improving the medication adherence behavior is corroborated by many research studies. In a study conducted by $\mathrm{R}$ Grant et al. in a type 2 DM cohort found that improved medication adherence behavior in patients kept their HbA1c levels under control compared to the non-adherent patients [19]. In a meta-analysis of medication adherence behavior studies conducted by Sapkota S, Brien $\mathrm{J}$-a et al. observed that educational intervention has shown a significant role in medication adherence behavior in diabetes patients in various research studies conducted globally. These findings strengthened the need of pharmacist mediated educational intervention in removing the inertia of medication nonadherence in type 2 DM patients [11]. The findings in our study also showed a statistically significant improvement in the Morisky Medication Adherence scores in test group patients compared to the patients in the control group. The findings of the study are a clear indication showing the importance of educational intervention in patients with chronic diseases such as diabetes.

A strict adherence to medication will improve the desired clinical outcomes such as glycaemic control in diabetes patients. This, in turn, will improve the health-related quality of life in diabetes patients. A healthy individual demonstrates productivity and satisfaction in the life.

\section{CONCLUSION}

Diabetes is a chronic disorder affects the social and emotional wellbeing of the patients if the glycaemic control is not adequately maintained. A structured education empowers the patients to take responsibility in adhering to their prescribed medication and thereby achieving the desired clinical outcomes. From the findings of our study, it can be concluded that structured education to patients in test group by a pharmacist has shown a significant improvement in medication adherence behavior, supporting the interventional educational role of the pharmacist.

\section{ACKNOWLEDGEMENT}

Authors are thankful to Principal Dr. B. Ramesh, SAC College of Pharmacy for providing necessary support to the study. We express our special thanks to Donald E. Morisky, ScD, ScM, MSPH, Professor and Former Chair, Department of Community Health Sciences, ULCA Fielding School of Public Health for MMAS 8 questionnaire to the study. Use of the CMMAS is protected by US copyright laws. Permission for use is required. A license agreement is available from Donald E. Morisky, 294 Lindura Court, Las Vegas, NV 89138-4632; dmorisky@gmail. com. We express our thanks to Mr. K V Ramanath, Associate Professor, SAC College of Pharmacy for guiding us with his valuable support throughout the study. We express our thanks to Dr. Shashikantha Bhat, MD general medicine to support us throughout the study with his timely suggestions and Dr. Adepu Ramesh Principal cum Director, Vikas College of Pharmaceutical Sciences to give his valuable inputs in bringing out our thesis.

\section{AUTHORS CONTRIBUTIONS}

1. K V Ramanath, M M Prabhu, Krishnadas N, K S R Pai. Monitoring of adverse reactions in geriatric south Indian patients in a tertiary care teaching hospital. Research Journal of Pharmaceutical, Biological and chemical sciences. 2016; 7:1: 1381-7

2. K V Ramanath, Saroj Paudel. Pharmacoeconomic evaluation and an audit of quality of life in hypertensive and diabetics in a rural tertiary care hospital. International journal of pharma sciences and research. 2015; 6: 11: 1352-60.

3. Y Yashaswini, R S Savitha, Jack Jose. Study on the assessment of knowledge on nutrition and dietary requirement in pregnant women. OMICS journal 2014.

\section{CONFLICTS OF INTERESTS}

Declared none

\section{REFERENCES}

1. American diabetes association, position statement, Diagnosis and Classification of Diabetes Mellitus. Diabetes Care 2004;27:5-10. 
2. International diabetes federation. $6^{\text {th }}$ edition. IDF Diabetes Atlas; 2013.

3. Sarah Wild, R Sicree. Global prevalence of diabetes. estimates for the year 2000 and projections for 2030. Diabetes Care 2004;27:5.

4. SS Gangwar, A Ahamed, I Patel. Assessment of medication knowledge and counselling in type 2 diabetes mellitus patients attending community pharmacy in rural North India. AJPSP 2013;4:47-57.

5. Malathy R, MP Narmadha, Ramesh S. Effect of a diabetes counselling programme on knowledge, attitude and practice among diabetic patients in erode district of South India. J Young Pharmacist 2011;3:65-72.

6. Stam DM, Graham JP. Important aspects of self-management education in patients with diabetes. Pharm Pract Manag Q 1997; 17:12-25.

7. Mazzuca SA, Moorman NH, Wheeler Ml. The diabetes education study: a controlled trial of the effects of diabetes education. Diabetes Care 1986;9:1-10.

8. Mahesh PA, Parthasarathi G. Medication adherence, textbook of clinical pharmacy practice, essential concepts and skills. Parthasarathi G, Hansen KN, Nahata MC, Orient Longman, Pvt Ltd; 2004. p. 54-71.

9. SZ Inamdar, RV Kulkarni, SR Karajgi. Medication adherence in diabetes mellitus: an overview on pharmacist role. Am J Adv Drug Delivery 2013:3:238-50.

10. R Adepu, SM Ari. Influence of structured patient education on therapeutic outcomes in diabetes and hypertensive patients. Asian J Pharm Clin Res 2010;3:174-8.

11. Sapkota S, Brien JA, Greenfield J. A systematic review of interventions addressing adherence to anti-diabetic medications in patients with type 2 diabetes-impact on adherence. Plos One 2015;10:1-17.

12. Morisky DE, Ang A, Krousel Wood M. Predictive validity of a medication adherence measure for hypertension control. J Clin Hypertension 2008;10:348-54

13. Berlowitz DR, Foy CG, Kazis LE, Bolin L, Conroy LB, Fitzpatrick P, Gure TR, et al. for the SPRINT Study Research Group. Impact of intensive blood pressure therapy on patient-reported outcomes: outcomes results from the SPRINT study. N Engl J Med 2017;377:733-44.

14. Morisky DE, DiMatteo MR. Improving the measurement of selfreported medication nonadherence final response. J Clin Epidemio 2011;64:258-63.

15. KV Ramanath. Impact of clinical pharmacist provided patient education on qol outcome in type ii diabetes mellitus in rural population. Asian J Pharm Clin Res 2011;4:15-20.

16. R Adepu, A Rasheed. Effect of patient counselling on quality of life in type 2 Diabetes mellitus patients in two selected south Indian community pharmacies: a study. Indian J Pharm Sci 2007;69:519-24.

17. R Adepu, Betsy AB. Impact of community pharmacy-based patient education on quality of life in type 2 diabetes mellitus. Int J Phytomed 2009;2:43-51.

18. Shobana R, Snehalatha C. Dietary profile of Urban South Indians and its relations with glycaemic status. Diabetes Res Clin Pract 1998;42:181-6.

19. R Grant, K Kleinman, AS Adams. Relationship between patient medication adherence and subsequent clinical inertia in type 2 diabetes glycaemic management. Diabetes Care 2007;30:4. 